\title{
La metarradio como recurso didáctico en educación primaria. El caso del programa La radio en clase
}

Metarradio as a teaching resource in primary education. Radio in the classroom programme proposal

\author{
José Antonio Sánchez-Hernández jantoniosanchez@um.es \\ http://orcid.org/0000-0002-7980-9288 \\ Facultad de Comunicación y Documentación; Departamento \\ de Información y Documentación; Universidad de Murcia (España)
}

David Sánchez-Martínez dav7d@hotmail.com

http://orcid.org/0000-0001-6233-1137

Consejería de Educación de la Comunidad Autónoma de la Región de Murcia (España)

\section{Resumen}

Este artículo analiza la adecuación del nuevo ecosistema radiofónico conceptualizado como metarradio al desarrollo de los contenidos curriculares en la enseñanza reglada de educación primaria. El análisis se realiza a partir de un programa radiofónico con la intervención de los 
escolares, desarrollado en cinco fases diferentes y donde se han formulado una serie de variables para la evaluación de los diferentes elementos estudiados. Los resultados señalan que esta iniciativa resulta bastante adecuada para la consecución de los estándares de aprendizaje evaluados y también favorece el conocimiento de la configuración del nuevo ecosistema mediático.

Palabras clave: Educomunicación; aprendizaje; currículo; metarradio; enseñanza.

\begin{abstract}
This article analyzes the adequacy of the new radio ecosystem defined as metaradio to the development of the curricular contents within the current education law given for primary education. The analysis is made by a radio program with the intervention of children from school, developed in five different phases and where a series of variables have been formulated for the evaluation of the different elements studied. The results indicate that this initiative highly contributes to the achievement of the evaluated learning standards and offers to the students an adequate knowledge of the configuration of the new media ecosystem.
\end{abstract}

Keywords: Educommunication; learning; curriculum; metaradio; teaching.

Los individuos precisan desarrollar las competencias necesarias para desenvolverse eficazmente en un mundo complejo y globalizado, a la vez que la sociedad requiere de individuos que dispongan de las aptitudes oportunas para poder ejercer una capacidad crítica y responsable que les permita participar activamente en la toma de decisiones. No nos referimos a un proceso puntual, sino que se conforma durante toda la vida de los individuos y que precisa ser reforzado por diversos agentes entre los que cobra una importancia capital la enseñanza reglada.

Al mismo tiempo, los medios de comunicación ejercen una notable influencia en la construcción de relatos colectivos que los individuos adoptan para interpretar la realidad. Hasta la configuración del actual ecosistema mediático, los individuos no participaban de manera activa en la construcción de estos imaginarios, sino que su actitud se limitaba a asumirlos de forma pasiva. Se está produciendo un importante proceso de transformación mediática: de los medios verticales y lineales se evoluciona hacia plataformas horizontales y abiertas a la participación 
de la audiencia y la desintermediación comunicativa auspiciada por la emergencia de los medios sociales. Se ha diseñado una nueva dimensión comunicativa que supera el modelo lineal emisor-receptor y donde podemos constatar la emergencia del prosumidor, un individuo que ya no solo consume los contenidos diseñados por los medios, sino que participa en el proceso de producción y expansión de los contenidos a través de diferentes canales y plataformas.

Esta transformación del proceso comunicativo marca la evolución de los medios a hipermedios (Scolari, 2008) y posibilita el desarrollo de nuevas narrativas transmedia (Jenkins, 2008). En el ámbito radiofónico se conforma un nuevo entorno comunicativo que supone la transformación de la radio en la metarradio (Sánchez-Hernández, 2017), donde se incluyen elementos multimedia e interactivos que superan las limitaciones hertzianas y sonoras de las emisoras tradicionales.

El panorama cambiante de la información y la comunicación precisa de ciudadanos preparados para comprender e interpretar las nuevas dinámicas y usos comunicativos. La alfabetización mediática adquiere una notable importancia en las primeras etapas educativas y no basta con que "el alumno aprenda a leer y a escribir sino también que adquiera competencias mediáticas, ya que va a vivir en un mundo digital rodeado de pantallas" (Aguaded, Marín-Gutiérrez y DíazParejo, 2015: 278).

La UNESCO en la Declaración de Grünwald (1982) recomienda la integración de la alfabetización mediática en los sistemas educativos. La Comisión Europea define la alfabetización mediática como

La capacidad de acceder, analizar y evaluar el poder de las imágenes, sonidos y mensajes con los cuales nos confrontamos diariamente, y que desempeñan un papel importante en la cultura contemporánea. Incluye la capacidad a nivel individual de comunicar utilizando los medios con competencias (Pérez y Varis, 2012: 5).

En este contexto se desarrolla nuestra investigación, consistente en valorar la idoneidad del nuevo ecosistema comunicativo radiofónico definido como metarradio para la consecución de los objetivos establecidos en el currículo de primer curso de educación primaria. Al tratarse de niños de seis años, hemos contemplado el uso de los medios como recurso didáctico y fuente de información atendiendo a su carácter creativo. Al mismo tiempo, se sugiere un uso más completo de la experiencia para etapas educativas posteriores que incluya un análisis crítico de los contenidos. 


\section{Metodología}

El análisis se realiza a partir del proyecto La radio en clase, desarrollado entre los meses de febrero y marzo de 2018 en la emisora municipal de radio de Las Torres de Cotillas (Murcia, España). Han participado dos grupos de primer curso de educación primaria del Centro de Educación Infantil y Primaria "San José" del municipio de Las Torres de Cotillas (Murcia, España): $1^{\circ} \mathrm{A}$ (26 alumnos) y $1^{\circ} \mathrm{B}$ (25).

El desarrollo del proyecto La radio en clase comprende cinco fases diferentes:

1. Reunión entre los profesionales de la emisora de radio y los tutores docentes de los alumnos para seleccionar temáticamente los contenidos y estructuración de los mismos en el programa radiofónico que van a realizar los alumnos.

2. Trabajo de preparación en el centro educativo coordinado por el profesor tutor. Comprende las labores de investigación sobre los temas a desarrollar, redacción de los contenidos y ensayo de locución de los mismos.

3. Visita de los alumnos a las instalaciones de la emisora municipal de radio donde se les muestran las diferentes dependencias y material técnico disponible. Además, se explica el funcionamiento del medio, la conformación de la parrilla de programación, el acceso a diferentes recursos sonoros, nociones básicas sobre edición de sonido y automatización de las emisiones, características de la emisión on line, alojamiento de los podcasts de los programas, redacción de las informaciones emitidas, utilización de redes sociales y aplicaciones móviles, etcétera.

4. Realización del espacio magacín. Los diferentes grupos de alumnos, con el guion y los contenidos preparados previamente en el aula, participan en la realización de este programa radiofónico en los estudios de la emisora de radio.

5. Colaboración en la redacción de una noticia para la web de la emisora incluyendo textos e imágenes, alojamiento del audio en la plataforma iVoox, y compartir los contenidos en Facebook y Twitter y en la aplicación móvil de la emisora.

Finalmente, se ha procedido a un doble proceso de evaluación de la actividad por parte de los profesores participantes y por los profesionales del medio mediante la conformación de un grupo conjunto de discusión. Por un lado, se han tomado en consideración los contenidos correspondientes al área de Lengua Castellana y Literatura, incluidos en el currículo de la educación primaria en la Comunidad autónoma de la Región de Murcia (C.A.R.M.), aprobado mediante Decreto 198/2014 de 5 de septiembre. En segundo lugar, se ha evaluado el nivel de 
conocimiento adquirido por los alumnos sobre los procesos y dinámicas comunicativas del medio.

Por tanto, estamos ante una actividad enmarcada en un soporte comunicativo que supera las limitaciones lineales de los medios tradicionales y que se adentra en nuevas dinámicas comunicativas. Los alumnos no solo preparan y desarrollan contenidos para ser emitidos sincrónicamente, sino que además participan en la elaboración de nuevos formatos narrativos que utilizan diferentes recursos expresivos: texto, audio e imágenes. Al mismo tiempo, los contenidos son compartidos en redes sociales permitiendo la expansión del relato con la retroalimentación propiciada por los usuarios que intervienen con sus comentarios y compartiendo la información.

\section{La educomunicación en el currículo de educación primaria en la región de} Murcia

La necesidad de abordar una alfabetización mediática en esta etapa educativa se pone de manifiesto en el propio Preámbulo del Decreto 198/214 de la C.A.R.M., al establecer que el desarrollo de habilidades cognitivas no es suficiente, sino que "es necesario adquirir desde edades tempranas competencias transversales, como el pensamiento crítico, la gestión de la diversidad, la creatividad o la capacidad de comunicar, y actitudes clave como la confianza individual, el entusiasmo, la constancia y la aceptación del cambio". El currículo apuesta por diseñar tareas y proyectos que supongan la utilización de tecnologías de la información y la comunicación en el proceso de aprendizaje que, además, las incluye como una de las propuestas metodológicas, junto al uso significativo de la lectura, escritura y la expresión oral mediante debates o presentaciones orales (artículo $13 \mathrm{~d}$ ).

El artículo 7.3 del Decreto 198/2014 de la C.A.R.M., señala que en la etapa de educación primaria, el alumnado cursará cinco áreas del bloque de asignaturas troncales en cada uno de los cursos de Educación Primaria: Ciencias de la Naturaleza, Ciencias Sociales, Lengua Castellana y Literatura, Matemáticas y Primera Lengua Extranjera. Dentro del bloque de asignaturas específicas, los alumnos deberán cursar tres áreas en todos los cursos de esta etapa: Educación Física, Educación Artística y Religión o Valores Sociales y Cívicos.

En el área de Lengua Castellana y Literatura el objetivo principal es desarrollar la competencia comunicativa del alumnado y aportarle los conocimientos y recursos necesarios para poder interactuar en cualquier situación comunicativa de la vida familiar, social y profesional. 


\section{El nuevo ecosistema radiofónico: la metarradio}

La mediación tecnológica del proceso comunicativo conforma un nuevo paradigma donde los nuevos canales, plataformas y dispositivos le han aportado unas características propias y diferenciadas, y en el que la multimedialidad, la atemporalidad y la ubicuidad cobran una especial importancia. En este sentido, Jenkins incide en las consecuencias que han generado las nuevas tecnologías mediáticas:

Han abaratado los costes de producción y distribución, han ampliado el repertorio de canales de distribución disponibles, y han facultado a los consumidores para archivar, comentar, apropiarse y volver a poner en circulación los contenidos mediáticos de maneras nuevas y poderosas (2008: 28).

El proceso comunicativo mediático se va conformando dentro de un entorno digital, hipertextual, multimedia, interactivo, al que Scolari conceptualiza como "comunicación hipermediática":

Al hablar de hipermediación no nos referimos tanto a un producto o un medio sino a procesos de intercambio, producción y consumo simbólico que se desarrollan en un entorno caracterizado por una gran cantidad de sujetos, medios y lenguajes interconectados tecnológicamente de manera reticular entre sí (2008: 113-114).

En este nuevo paradigma comunicativo se sitúa el proceso de transformación mediática y se va configurando la metarradio que sobrepasa el concepto de medio tradicional al sustentar y amalgamar la participación de diferentes agentes, plataformas y canales, a los que se le otorgan distintos papeles en la conformación de un entorno comunicativo dotado de una identidad propia que supera la suma individual de cada uno de los elementos (SánchezHernández, 2017).

Atendiendo a todos estos factores, se hace preciso conceptualizar el término metarradio como

El paradigma comunicativo radiofónico que supera las emisiones hertzianas tradicionales y se expande por nuevos canales, soportes y plataformas creando un entorno comunicativo global, accesible de manera ubicua a través de múltiples dispositivos, que rompe la supremacía sincrónica para proporcionar un acceso personalizado a los contenidos, predominando la expresión sonora pero influenciada y complementada con la posibilidad de incluir elementos textuales y visuales, y utilizando nuevas narrativas y formatos gracias a 
las múltiples posibilidades de interacción y participación de la audiencia (Sánchez-

Hernández, 2017).

En definitiva, nos encontramos ante una nueva realidad comunicativa mediática en continuo estado de evolución, redefinición y caracterización, asentada en la estructura y dinámicas prevalentes de la radio tradicional pero tecnológicamente transformada en un nuevo modelo en el que se generan nuevos modos de producción, expresión, distribución y consumo de contenidos, y nuevas formas de participación de la audiencia en cada uno de estos procesos (Sánchez-Hernández, 2017).

Ante este panorama comunicativo cambiante, las administraciones tienen que ofrecer una respuesta formativa para que los ciudadanos consigan adquirir este tipo de nuevas competencias, en una propuesta doble: mediante programas de alfabetización mediática dirigidos a la ciudadanía en general y a través de la enseñanza reglada incluyendo los contenidos en el currículo educativo.

La UNESCO destaca que los medios de comunicación "tienen un importante impacto en el aprendizaje a lo largo de la vida y por lo tanto los ciudadanos necesitan tener un conocimiento básico de las funciones de los medios y otros proveedores de información y capacidad para poder evaluarlos" (2011: 16). De esta manera, "podrán desarrollar un pensamiento crítico y un aprendizaje de destrezas a lo largo de toda la vida para socializar y convertirse en ciudadanos activos" (2011: 185).

\section{Resultados}

Los resultados de la investigación aparecen recogidos en tres áreas diferentes: valoración de las orientaciones metodológicas, evaluación de los contenidos de Lengua Castellana y Literatura, y determinación del conocimiento del medio de comunicación.

\section{Evaluación orientaciones metodológicas}

En cuanto a las orientaciones metodológicas que recomienda el Decreto 198/2014 de la C.A.R.M., la actividad realizada ha resultado ser muy adecuada para:

a. Realizar trabajos y presentaciones a nivel individual y en equipo para la realización de un producto significativo mediante la búsqueda, selección y organización de información.

b. debates previamente preparados en la actividad cotidiana del aula. 
c. Evaluar las prácticas orales de los demás; para integrar las Tecnologías de la Información y la Comunicación en el aula para analizar discursos y debates audiovisuales y evaluar discursos propios y ajenos grabados.

d. Generar actitudes de cooperación y responsabilidad asumiendo cada miembro el rol correspondiente dentro del grupo, aceptando las diferencias con respeto y tolerancia hacia las ideas y aportaciones ajenas.

\section{Evaluación de los contenidos de Lengua Castellana y Literatura}

Los contenidos de esta área aparecen recogidos en cinco bloques diferentes que comprenden la evaluación de diferentes estándares de aprendizaje relacionados con la comunicación oral, comunicación escrita, conocimiento de la lengua y educación literaria.

Bloque 1. Comunicación oral: hablar y escuchar

Los resultados de la evaluación ponen de manifiesto que esta actividad resulta muy adecuada para contribuir al desarrollo de los contenidos del bloque 1 "Comunicación oral: hablar y escuchar", en el primer curso de Educación Primaria, con una valoración media de 4,7 sobre 5 puntos (Tabla 1).

\begin{tabular}{|l|l|}
\hline \multicolumn{1}{|c|}{ BLOQUE 1. COMUNICACIÓN ORAL: HABLAR Y ESCUCHAR (1) } & \\
\hline $\begin{array}{l}\text { Situaciones de comunicación, espontáneas o dirigidas, respetando las normas de } \\
\text { comunicación }\end{array}$ & 5 \\
\hline $\begin{array}{l}\text { Estrategias y normas para el intercambio comunicativo: escucha, respeto por el turno de } \\
\text { palabra }\end{array}$ & 5 \\
\hline Interacciones en la comunicación & 5 \\
\hline Comprensión y expresión de mensajes verbales y no verbales en la comunicación oral & 4 \\
\hline Expresión de mensajes verbales: respuestas a preguntas & 5 \\
\hline Comprensión de textos orales & 4 \\
\hline Ampliación del vocabulario & 5 \\
\hline $\begin{array}{l}\text { Expresión y producción de textos orales adaptados a su edad: poesías, adivinanzas, } \\
\text { canciones, dramatizaciones }\end{array}$ & 5 \\
\hline Comprensión de instrucciones orales & 4 \\
\hline Reproducción de textos breves, sencillos, que estimulen el interés del niño & 5 \\
\hline Producción de textos orales sencillos & 5 \\
\hline
\end{tabular}

Tabla 1. Bloque 1: Comunicación oral: hablar y escuchar. Elaboración propia, 2018. 
Los diferentes contenidos que se han abordado en la realización de esta actividad se han concretado en las siguientes acciones:

1. Situaciones de comunicación, espontáneas o dirigidas, respetando las normas de comunicación: los alumnos han tenido que responder a preguntas espontáneas que no habían trabajado previamente, sobre aficiones, gustos musicales y preferencias literarias. Se han expresado con bastante soltura y han entablado un diálogo continuado sobre estos temas.

2. Estrategias y normas para el intercambio comunicativo: escucha, respeto por el turno de palabra: han realizado una escucha activa que les ha permitido establecer un diálogo continuado y han respetado el turno de palabra de los demás participantes en la conversación generada.

3. Interacciones en la comunicación: han desarrollado una interacción fluida, aunque han precisado la dinamización por parte del conductor del programa.

4. Comprensión y expresión de mensajes verbales y no verbales en la comunicación oral: la oralidad del medio radiofónico ha propiciado que los alumnos hayan articulado sus intervenciones verbalmente de manera que sean claras y comprensibles para los demás. Las expresiones no verbales solo han sido percibidas por el resto de alumnos y profesionales que han realizado el programa pero no así por la audiencia. Por tanto, los alumnos han empleado tanto recursos lingüísticos como no lingüísticos para comunicarse.

5. Expresión de mensajes verbales: respuestas a preguntas: la dinámica introducida en la exposición de contenidos se ha articulado en torno a contenidos de interés para el alumno, con lo que se ha facilitado el diálogo posterior sobre aquellos aspectos de la exposición que no habían quedado lo suficientemente claros.

6. Comprensión de textos orales: la actividad favorece el interés y atención del alumno sobre la exposición de los demás intervinientes ya que, en determinadas ocasiones, tiene que desarrollar sus intervenciones a partir de los contenidos aportados por los demás, facilitando la comprensión de los mensajes orales.

7. Ampliación del vocabulario: la selección y elaboración de contenidos y la escucha activa sobre las exposiciones de los demás contribuye a enriquecer el vocabulario de los alumnos.

8. Expresión y producción de textos orales adaptados a su edad: poesías, adivinanzas, canciones, dramatizaciones: se ha desarrollado la exposición de textos literarios aunque no se ha trabajado la creatividad con la producción de esta serie de contenidos.

9. Comprensión de instrucciones orales: la dinámica del programa ha requerido que, en determinados momentos, el conductor facilite diferentes instrucciones para corregir o sugerir determinados aspectos.

Question, Vol. 1, N. ${ }^{\circ}$ 61, enero-marzo 2019. ISSN 1669-6581

Instituto de Investigaciones en Comunicación | Facultad de Periodismo y Comunicación Social | Universidad Nacional de La Plata La Plata | Buenos Aires | Argentina

Página 9 de 16 
10. Reproducción de textos breves, sencillos, que estimulen el interés del niño: los alumnos han participado activamente en la selección de los textos lo que ha incrementado su interés.

11. Producción de textos orales sencillos: los alumnos han tenido que describir cómo es su colegio, cómo se desarrolla una jornada diaria en el centro educativo, presentar una canción de su cantante preferido, lo que ha contribuido a la producción de textos sencillos para ser expresados de manera oral.

Bloque 2. Comunicación escrita: leer

Los resultados de la evaluación indican que esta actividad resulta muy adecuada para contribuir al desarrollo de los contenidos del bloque 2, en el primer curso de educación primaria, con una valoración media de 4,3 sobre 5 puntos (Tabla 2).

\begin{tabular}{|l|l|}
\hline \multicolumn{1}{|c|}{ BLOQUE 2. COMUNICACIÓN ESCRITA: LEER } & \\
\hline Consolidación del sistema de lecto-escritura: codificación y decodificación & 5 \\
\hline $\begin{array}{l}\text { Comprensión de textos leídos: órdenes y breves instrucciones, textos narrativos y } \\
\text { expositivos }\end{array}$ & 4 \\
\hline Adquisición de la ortografía natural & 4 \\
\hline Lectura de diferentes textos & 4 \\
\hline Estrategias para la comprensión lectora: título, ilustraciones, resúmenes & 4 \\
\hline Hábito lector & 5 \\
\hline Selección de textos según el gusto personal & 4 \\
\hline Uso de la biblioteca & 5 \\
\hline Uso de las TIC como instrumento de aprendizaje en tareas sencillas & 4 \\
\hline
\end{tabular}

Tabla 2. Bloque 2: Comunicación escrita: leer. Elaboración propia, 2018.

A continuación, recogemos cómo se han materializado los diferentes contenidos dentro de la actividad:

1. Consolidación del sistema de lecto-escritura: refuerza la lecto-escritura al tener que leer en voz alta textos de diferentes estilos con la fluidez, ritmo y entonación adecuados.

2. Comprensión de textos leídos: órdenes y breves instrucciones, textos narrativos y expositivos: contribuye a la lectura comprensiva de los textos elaborados por los propios alumnos o seleccionados de otras fuentes bibliográficas ya que se fomenta el diálogo posterior a la exposición mediante la formulación de preguntas sobre diferentes aspectos abordados en el texto. 
3. Adquisición de la ortografía natural: facilita la fijación de la ortografía correcta al tener que seleccionar diferentes textos y realizar una sencilla redacción para su exposición oral en el programa radiofónico.

4. Lectura de diferentes textos: contribuye a que el alumno lea diferentes textos para seleccionar determinados contenidos y que lo haga de manera comprensiva.

5. Estrategias para la comprensión lectora: título, ilustraciones, resúmenes: Los alumnos han tenido que resumir lo más destacado de un texto, describir las ilustraciones que contiene y ofrecer las ideas principales a modo de titulares.

6. Hábito lector: la actividad fomenta el hábito lector, aunque sería necesario darle continuidad para valorar mejor los resultados.

7. Selección de textos según el gusto personal: los alumnos aportan aquellos contenidos que le atraen y explican los motivos de la selección efectuada.

8. Uso de la biblioteca: se han utilizado los recursos disponibles en la biblioteca del aula y centro para seleccionar cuentos y adivinanzas.

9. Uso de las TIC como instrumento de aprendizaje en tareas sencillas: parte de la información, como la biografía de sus cantantes favoritos, han tenido que obtenerla de internet con lo que se ha fomentado el uso de las TIC.

Bloque 3. Comunicación escrita: escribir

Los resultados de la evaluación indican que esta actividad resulta bastante adecuada para contribuir al desarrollo de los contenidos del bloque 3 Comunicación escrita: escribir, en el primer curso de educación primaria, con una valoración media de 3,6 sobre 5 puntos (Tabla 3).

\begin{tabular}{|l|l|}
\hline \multicolumn{1}{|c|}{ BLOQUE 3. COMUNICACIÓN ESCRITA: ESCRIBIR } & \\
\hline Producción de textos para comunicar experiencias y necesidades & 5 \\
\hline Escritura de palabras, oraciones y pequeños textos & 4 \\
\hline Separación de palabras & 5 \\
\hline Dictados & 0 \\
\hline Revisión y mejora del texto & 4 \\
\hline Uso de las TIC & 4 \\
\hline
\end{tabular}

Tabla 3. Bloque 3: Comunicación escrita: escribir. Elaboración propia, 2018.

Los diferentes contenidos de esta actividad se han materializado de la siguiente manera: 
1. Producción de textos para comunicar experiencias y necesidades: la actividad ha incluido la elaboración de textos descriptivos sobre su experiencia diaria en el colegio, describiendo las instalaciones y dependencias de centro.

2. Escritura de palabras, oraciones y pequeños textos: la expresión escrita ha resultado determinante para confeccionar los diferentes relatos, con la utilización de las palabras adecuadas, construcción de oraciones y establecer las conexiones necesarias entre ellas para conformar una unidad narrativa coherente y cohesionada.

3. Separación de palabras: los alumnos han sido capaces de identificar diferentes palabras incluidas en los relatos, como nombres propios.

4. Dictados: no se ha desarrollado este contenido en esta actividad.

5. Revisión y mejora del texto: se ha procedido a la revisión de los diferentes textos, sencillos y breves, para corregir aquellos errores cometidos por los alumnos, tanto a nivel sintáctico, como gramatical.

6. Uso de las TIC: han utilizado Internet para buscar información básica.

Bloque 4. Conocimiento de la lengua

Los resultados de la evaluación indican que esta actividad resulta adecuada para contribuir al desarrollo de los contenidos del bloque 4 Conocimiento de la lengua, en el primer curso de educación primaria, obteniendo una valoración media de 3,4 sobre 5 puntos (Tabla 4).

\begin{tabular}{|l|l|}
\hline \multicolumn{1}{|c|}{ BLOQUE 4. CONOCIMIENTO DE LA LENGUA } & \\
\hline Lectura y escritura de palabras y oraciones & 4 \\
\hline Unión de letras para formar sílabas y de sílabas para formar palabras & 5 \\
\hline Las relaciones de género y número & 4 \\
\hline Ortografía: uso de la mayúscula en los nombres propios & 4 \\
\hline Uso de programas educativos digitales & 0 \\
\hline
\end{tabular}

Tabla 4. Bloque 4. Conocimiento de la lengua. Elaboración propia, 2018.

Los contenidos se han desarrollado de la siguiente manera:

1. Lectura y escritura de palabras y oraciones: la redacción de pequeños textos sobre temas de interés para los alumnos ha contribuido notablemente al desarrollo de sus competencias lingüísticas. 
2. Unión de letras para formar sílabas y de sílabas para formar palabras: al mismo tiempo, la necesidad de construir relatos ha favorecido el interés por construir palabras con las que desarrollar la narración.

3. Las relaciones de género y número: los relatos construidos por los alumnos han precisado que prestaran especial atención a la concordancia entre género y número.

4. Ortografía: Uso de la mayúscula en los nombres propios: los distintos textos que han realizado han incluido nombres propios de personas y se ha incidido en que se escriben con mayúscula.

5. Uso de programas educativos digitales: para la realización de esta actividad no se ha incluido el manejo de este tipo de programas

\section{Bloque 5. Educación literaria}

Los resultados de la evaluación indican que esta actividad resulta muy adecuada para contribuir al desarrollo de los contenidos del bloque 5 "Educación literaria", en el primer curso de educación primaria, obteniendo una valoración media de 4,2 sobre 5 puntos (Tabla 5).

\begin{tabular}{|l|l|}
\hline \multicolumn{1}{|c|}{ BLOQUE 5. EDUCACIÓN LITERARIA } & \\
\hline Uso de los textos literarios como fuente de disfrute & 4 \\
\hline $\begin{array}{l}\text { Lectura guiada de textos narrativos de tradición oral, de pequeños poemas y de textos } \\
\text { breves de literatura infantil }\end{array}$ & 4 \\
\hline Dramatización & 3 \\
\hline Memorización y recitado de poemas con el ritmo y entonación adecuados & 5 \\
\hline Memorización de textos literarios: cuentos, canciones & 5 \\
\hline
\end{tabular}

Tabla 5. Bloque 5. Educación Literaria. Elaboración propia, 2018.

Los contenidos se han desarrollado de la siguiente manera:

1. Uso de los textos literarios como fuente de disfrute: la selección de textos por parte de los alumnos se ha reforzado con la exposición radiofónica al tener que conseguir que agradaran a los oyentes y demás alumnos participantes en el programa. En este sentido, han apreciado el valor de los textos literarios y han disfrutado al observar el interés mostrado por los demás.

2. Lectura guiada de textos narrativos de tradición oral, de pequeños poemas y de textos breves de literatura infantil: la selección literaria que los alumnos han realizado para este programa incluía poemas sencillos y breves narraciones adaptadas a su edad. 
3. Dramatización: los alumnos han recitado textos incluyendo los elementos de ambiente y situación de las historias, pero no así la escenificación de los mismos al tratarse de un medio oral.

4. Memorización y recitado de poemas con el ritmo y entonación adecuados: las intervenciones de algunos de los alumnos han estado basadas en interpretar textos con la entonación y el ritmo adecuado que habían memorizado previamente.

5. Memorización de textos literarios: cuentos, canciones: algunos de los alumnos han memorizado los contenidos de su intervención lo que ha aportado naturalidad expresiva a la narración de los textos literarios.

3. Determinación del conocimiento del medio de comunicación

Los resultados de la evaluación indican que esta actividad resulta muy adecuada para el conocimiento del nuevo ecosistema mediático que hemos conceptualizado como metarradio, obteniendo una valoración media de 4,1 sobre 5 puntos (Tabla 6).

\begin{tabular}{|l|l|}
\hline \multicolumn{1}{|c|}{ CONOCIMIENTO DEL MEDIO DE COMUNICACIÓN } & \\
\hline $\begin{array}{l}\text { Conocimiento del nuevo entorno comunicativo radiofónico: broadcast, emisión online, } \\
\text { página web, aplicación móvil, redes sociales }\end{array}$ & 4 \\
\hline Buscar, seleccionar y editar contenidos en formato radiofónico & 4 \\
\hline $\begin{array}{l}\text { Elaboración de sencillas piezas informativas para website que incluyan texto, audio e e } \\
\text { imágenes }\end{array}$ & 4 \\
\hline Alojamiento del audio del programa en la plataforma iVoox & 5 \\
\hline $\begin{array}{l}\text { Acceso a los contenidos alojados en la página web y en iVoox y compartir los mismos en } \\
\text { Facebook y Twitter }\end{array}$ & 5 \\
\hline $\begin{array}{l}\text { Observación y análisis de la repercusión obtenida (compartido) y de los comentarios que } \\
\text { ha suscitado }\end{array}$ & 4 \\
\hline Desarrollo de una capacidad crítica en la valoración de los contenidos mediáticos & 3 \\
\hline
\end{tabular}

Tabla 6: Conocimiento del medio de comunicación. Elaboración propia, 2018.

Los alumnos han sido capaces de conocer y experimentar con el nuevo ecosistema radiofónico:

1. Elaborando contenidos para ser emitidos de manera sincrónica en la emisora de radio.

2. Redactando una noticia sobre la emisión del programa radiofónico en la web de la emisora, incluyendo texto, audio e imágenes.

Question, Vol. 1, N. ${ }^{\circ}$ 61, enero-marzo 2019. ISSN 1669-6581

Instituto de Investigaciones en Comunicación | Facultad de Periodismo y Comunicación Social | Universidad Nacional de La Plata La 
3. Alojando el podcast en plataformas de audio (iVoox).

4. Compartiendo los contenidos en redes sociales (Twitter y Facebook) y mediante la aplicación móvil de la emisora.

5. Desarrollando de manera incipiente una capacidad crítica frente a los contenidos mediáticos.

\section{Conclusiones}

La incorporación de proyectos radiofónicos al desarrollo de competencias incluidas en el currículo de primer curso de educación primaria, constituye una excelente herramienta para trabajar de manera satisfactoria los contenidos incluidos en el mismo. Supone un cambio de paradigma importante al situar a los alumnos en un entorno comunicativo totalmente diferente al del aula, donde sus intervenciones tienen una dimensión abierta y pública, al ser escuchadas por una audiencia amplia que supera al entorno habitual integrado por el docente y los compañeros de aula.

Este modelo contribuye no solo al conocimiento y utilización de los recursos radiofónicos para conformar una nueva dimensión comunicativa para el alumno, sino que ayudan a trabajar los contenidos curriculares del área de Lengua Castellana y Literatura de una forma distinta y bastante adecuada para la consecución de los estándares de aprendizaje evaluados.

Los resultados, referidos a alumnos de primer curso de educación primaria de la C.A.R.M., ponen de manifiesto que este proyecto que supone la utilización del medio de comunicación radiofónico como soporte educativo, es muy adecuado para trabajar aquellos contenidos que hacen referencia a la comunicación oral. Al mismo tiempo, fomenta de manera muy adecuada la consecución de objetivos que se refieren a la comprensión lectora, y resulta un recurso muy adecuado para la construcción de textos breves y sencillos. De la misma manera, constituye un soporte bastante adecuado para el conocimiento de la lengua y contribuye notablemente a la educación literaria.

Los resultados obtenidos se adaptan a las capacidades de los alumnos que han participado en la actividad y demuestran la notable importancia de establecer sinergias permanentes entre los medios de comunicación y los centros educativos. Al tratarse de niños de seis años, hemos contemplado el uso de los medios como recurso didáctico y fuente de información atendiendo a su carácter creativo. Se sugiere profundizar en la utilización de este tipo de experiencias para etapas educativas superiores que incluyan un análisis crítico de los mensajes mediáticos. 


\section{Notas}

(1) Las tablas reflejan las frecuencias de puntuación para cada ítem con las siguientes valoraciones: "No adecuada" (0-

1), "Poco adecuada" (1-2,4), "Adecuada" (2,5-3), "Bastante adecuada" (3-4) y "Muy adecuada" (4-5).

\section{Bibliografía}

Aguaded, I.; Marín-Gutiérrez, I. y Díaz-Parejo, E. (2015). La alfabetización mediática entre estudiantes de primaria y secundaria en Andalucía (España). RIED. Revista Iberoamericana de Educación a Distancia, 18(2), 275-298. doi: https://doi.org/10.5944/ried.18.2.13407

Boletín Oficial de la Región de Murcia (6 de septiembre de 2017). Decreto 198/2014, currículo de la Educación Primaria en la Comunidad Autónoma de la Región de Murcia, 206.

Jenkins, H. (2008). Convergence culture. La cultura de la convergencia de los medios de comunicación. Barcelona: Paidós.

Organización de las Naciones Unidas para la Educación, la Ciencia y la Cultura (UNESCO) (2011). Alfabetización mediática e institucional. Currículum para profesores. Recuperado de http://unesdoc.unesco.org/images/0021/002160/216099S.pdf

Pérez, J. M. y Varis, T. (2012). Alfabetización mediática y nuevo humanismo. Barcelona: Editorial UOC.

Sánchez-Hernández, J. A. (2017). La metarradio como un nuevo paradigma radiofónico conformado por la convergencia con Internet y la telefonía móvil. En Munt, M. y Camarero, E. (coords.). Nuevos tratamientos informativos y persuasivos (pp. 351-362). Madrid: Editorial Tecnos.

Scolari, C. (2008). Hipermediaciones. Elementos para una Teoría de la Comunicación Digital Interactiva. Barcelona: Gedisa. 